\title{
Pulmonary regurgitation after repaired tetralogy of Fallot: surgical versus percutaneous treatment
}

\author{
Juan Antonio Meca Aguirrezabalaga, Jacobo Silva Guisasola, Rocío Díaz Méndez, \\ Alain Eliott Escalera Veizaga, Daniel Hernández-Vaquero Panizo
}

Department of Cardiac Surgery, Heart Area, Hospital Universitario Central de Asturias, Oviedo, Spain

Contributions: (I) Conception and design: All authors; (II) Administrative support: None; (III) Provision of study materials or patients: None; (IV) Collection and assembly of data: All authors; (V) Data analysis and interpretation: All authors; (VI) Manuscript writing: All authors; (VII) Final approval of manuscript: All authors.

Correspondence to: Jacobo Silva Guisasola, MD. PhD. Head Cardiac Surgery Unit, Heart Area Department, Hospital Universitario Central de Asturias, Avenida Hospital Universitario Central de Asturias s/n, Oviedo 33011, Spain. Email: jsilva8252@yahoo.es.

\begin{abstract}
Pulmonary regurgitation is the most important sequellae after correction of Tetralogy of Fallot and has a considerable impact over the right ventricle. Surgery has demonstrated low early mortality after pulmonary valve replacement and good long-term outcomes, remaining nowadays the gold standard treatment of pulmonary regurgitation in rTOF patients. Nevertheless, transcatheter pulmonary valve implantation has emerged as a new, safe and efficient alternative to surgical valve replacement. In this review article, we try to evaluate and compare both techniques to find out which is the best therapeutic option in this patients.
\end{abstract}

Keywords: Tetralogy of Fallot (TOF); pulmonary regurgitation; pulmonary valve replacement; transcatheter pulmonary valve; congenital heart disease

Submitted Dec 11, 2019. Accepted for publication Feb 15, 2020.

doi: $10.21037 /$ atm.2020.03.81

View this article at: http://dx.doi.org/10.21037/atm.2020.03.81

\section{Introduction}

Tetralogy of Fallot (TOF) is the most common cyanotic congenital heart disease (1). The anatomic composition of this disease was first described by Etienne-Louis Fallot in 1888 (2). Due to an anterocephalad displacement of the outlet septum, we can find certain anatomical features that constitute the Tetralogy of Fallot:

(I) Large anterior malaligned ventricular septal defect (VSD; it consists in a defect (almost always unrestrictive) between the conal septum and ventricular septum;

(II) Right ventricular (RV) outflow tract obstruction (RVOT). The conal septum projects into the RVOT contributing to narrowing of the infundibulum. Frequently, we find a bicuspid pulmonary valve;

(III) RV hypertrophy, because of exposition to systemic pressure;
(IV) Dextroposition of the aorta, lying more anteriorly relative to pulmonary valve;

(V) Other cardiac abnormalities may coexist as atrial septal defects, coronary anomalies, right aortic arch, multiple venrticular septal defects and others (3).

\section{Surgical history of tetralogy of Fallot}

The first step in the treatment of TOF was taken by Helen Taussig, Alfred Blalock and Vivien Thomas in 1945, creating an arterial shunt diverting arterial blood flow from the subclavian artery to the pulmonary artery (4).

Lillehei reported the first complete intracardiac repair of TOF in 1954 utilising a large RV incision and transannular patch (5).

The first successful repair using a heart-lung machine was accomplished by Kirklin and associates in 1955 (6).

The trans-atrial anatomic repair of 1963 , was popularised 
by Roger Mee, reporting a mere $0.5 \%$ operative mortality and a 47 month survival of $97.5 \%$ (7).

In the following years there were many surgeons who shed light on the repair of this pathology (Ross, Somerville, Barrat-Boyes, Neutze, Castaneda) and thanks to which we have reached the current results.

Currently, transatrial and transpulmonary approaches have replaced ventriculotomy in an effort to minimize RV dysfunction and scarring. Whenever possible, annularsparing and pulmonary valve-sparing strategies have been preferentially adopted nowadays.

Patients with TOF typically undergo VSD closure and relief of the RVOTO within the first 6 months of life. The type of surgery to relieve the RVOTO will vary depending on the patient's individual anatomy: patients with a relatively normal pulmonary valve annulus may undergo RVOT muscle bundle resection and an annular sparing approach, while those with severe pulmonary annular hypoplasia and infundibular stenosis will undergo a transannular patch (TAP) and muscle bundle resection. The patch is often carried out onto the branch pulmonary arteries as well. Patients with TOF/pulmonary atresia or those with an anomalous coronary artery crossing the RVOT may require placement of an RV-to-pulmonary-artery conduit.

\section{Natural evolution of repaired tetralogy of Fallot}

Despite the success in the surgery and achieve both anatomical and physiological correction, there are still complications in late survivors such as pulmonary regurgitation conditioning $\mathrm{RV}$ dysfunction, recurrent obstruction of the RV outflow tract, arrhythmias, sudden death, and aortic dilation and regurgitation.

Over time, rTOF patients will frequently develop some degree of RVOT dysfunction and certain degree of PR. In the first years after surgery, these residual lessions are well tolerated. Years later, there is an overload of the RV and depression of myocardial function, leading to systolic ventricular deterioration and establishing myocardial fibrosis that converts RV dysfunction into irreversible.

Due to the close interrelation between the right ventricle and the left ventricle, the lack of electromechanical synchronization of the former ends up in systolic dysfunction of the latter.

A minority group of rTOF patients will have pulmonary stenosis (PS) as their main residual lesion. Other group of rTOF patients with an RV-PA conduit will suffer a progressive conduit dysfunction with stenosis as the main lesion, with or without concomitant regurgitation.

\section{Indication and timing for pulmonary valve replacement (PVR)}

The main indication of a new surgery is the existence of significant pulmonary regurgitation with clinical symptoms (NYHA class III or IV). In asymptomatic patients, pulmonary valve replacement is indicated by progressive right ventricle dilatation, or dysfunction, new onset or progression of arrythmias, and developement or progression of tricuspid valve regurgitation. All these indications and summarized in the guidelines of the European Society of Cardiology (8), the American College of Cardiology/ American Heart Association (9) and the Canadian Cardiovascular Society (10).

PVR can be achieved with a low early mortality, but it must be done before there is irreversible RV dysfunction and a greater propensity for VT and sudden death. It is essential to identify risk factors and thus determine the optimal timing of PVR. Cesnjevar et al. (11) talk about a "point of no return", where the function of the RV is irreversibly affected despite performing PVR, even affecting the function of the LV.

Many studies have measured preoperative RV size thresholds in rTOF (11-17).

A study using cardiac magnetic resonance in rTOF adults showed after PVR, a significant reduction in RV volumes, while the RV systolic function was not modified. However, in patients with a $\mathrm{RV}$ end-diastolic volume $>170 \mathrm{~mL} / \mathrm{m}^{2}$ or a RV end-systolic volume $>85 \mathrm{~mL} / \mathrm{m}^{2}$ before $\mathrm{PVR}$, the RV volumes did not return to normal after PVR. Normalisation of $\mathrm{RV}$ volumes was observed after surgery when it was performed before the end-diastolic RV volume exceded $160 \mathrm{~mL} / \mathrm{m}^{2}$ or the end-systolic $\mathrm{RV}$ volume was greater than $82 \mathrm{~mL} / \mathrm{m}^{2}(18)$.

In other CMR study, Frigiola et al. examined 71 rTOF before and 1 year after PVR. Their conclusión was performing surgery with an end-diastolic volume $<150 \mathrm{~mL} / \mathrm{m}^{2}$ leads to normalisation of RV volumes, recovery of biventricular function, and exercise capability (19).

Other tool to assess the timing of surgery is the QRS lenght. It can be lengthened years after surgery, frequently associated with the increase of RV volume and mass. Gatzoulis et al. realized that a QRS longer than 180 ms may be a warning sign of ventricular arrhythmias and sudden death, while a QRS no longer than $180 \mathrm{~ms}$ has a negative predictive value of $100 \%$ for these events (20). 


\section{Surgical pulmonary valve replacement}

Surgical PVR can be carried out with both bioprostheses and mechanical prostheses. Bioprostheses have become the best option for PVR, but deterioration of the structural valve is still inevitable over time. Despite of this structural valve deterioration, it continues to be the type of prosthesis preferred by most surgeons.

Dehaki et al. (21) reviewed long-term outcomes of mechanical prosthesis placed in the pulmonary position in patients with congenital heart disease. They evaluated 121 with a mean age at the time of surgery was $23.1-7.9$ years. The median valve size was $25 \mathrm{~mm}$. All of them were discharged on oral anticoagulation with target INR of 2.5-3.5. There were no deaths during the mean follow-up of 7.0-1.9 years. Mechanical valve malfunction occurred in 10 patients (1 pannus ingrowth and 9 thrombosis). There were 3 self- limiting bleeding events.

In other study, Pragt et al. (22) analyzed data on 364 patients with pulmonary mechanical prostheses. Median follow-up was 4.26 years, mean age at implantation was $27.16 \pm 12.2$ years. Freedom from valvular thrombosis was $91 \%$ at 5 years and $86 \%$ at 10 years post-PVR. Freedom from reoperation was $97 \%$ at 5 years post-PVR and $91 \%$ at 10 years.

Both studies conclude that mechanical valve prosthesis are safe and have a low rate of thrombotic complications.

The limited bioprosthesis life is related to valve type and age at implantation $(23,24)$. Average time to reoperation is around 15 years for most adult rTOF patients $(25,26)$. The ring of the bioprosthesis could be a good landing structure for a future valve in valve percutaneous pulmonary valve implantation (PPVI). If we are thinking about a future PPVI it is important to implant the largest possible valve.

In high-volume and experienced centers, the risk of a reoperation after rTOF is low with good long-term outcomes, but the morbidity of a new open cardiac surgery is significant, and these operations become technically more complex with every new surgery because of adhesions, fibrosis and scaring.

Ferraz Cavalcanti et al. (25) published a large meta-analysis with 3,118 patients with rTOF that underwent PVR. The pooled outcomes were: 30 -day mortality was $0.87 \%$; 5 -year mortality was $2.2 \% ; 5$-year re-PVR was $4.9 \%$. The outcomes of this meta-analysis showed that after PVR both the RV and $\mathrm{LV}$ experience an improvement in their volumes and function; QRS length is shortened; and NYHA class improves.

Lee et al. (15) analyzed retrospectively a cohort of 170 patients who underwent PVR for chronic PR. The median age at the time of PVR was 16.7 years. Followup completeness was $95 \%$, and the median follow-up duration was 5.9 years. The overall and event-free survival at 10 years was $98 \%$ and $70 \%$, respectively. Postoperative magnetic resonance revealed a significant improvement in biventricular function and $\mathrm{RV}$ volumes. A value greater than $168 \mathrm{~mL} / \mathrm{m}^{2}$ for the end-diastolic volume index of $\mathrm{RV}$ (EDVI) and $80 \mathrm{~mL} / \mathrm{m}^{2}$ for the end-systolic volume index of RV (ESVI) were the threshold values for irreversibility of damage. A higher preoperative ESVI RV was identified as a single independent risk factor for a suboptimal outcome.

Lim et al. (27) tried to find out the optimal timing of PVR analyzing clinical results of a cohort of 58 patients who underwent PVR after rTOF. 30-day mortality was $(2.5 \%)$. Major complication occurred in three patients. Follow-up was performed for $2.5 \pm 2.4$ years. There was no late death. Postoperative symptomatic group showed older age at repair of TOF, older age at PVR, longer interval between repair of TOF and PVR and longer hospital stay than postoperative asymptomatic group.

These are just a few examples of studies with surgical cohorts in which the low PVR mortality is more tan evident. These studies go beyond the study of the mortality and try to analyze the impact of surgery on the RV and to infer from them the optimal time to perform surgery.

All the results of surgical studies are summarized in Table 1.

\section{PPVI}

PPVI was introduced by Bonhoeffer et al. (38) in 2000 in an attempt to minimize the number of reoperations in patients with complex congenital heart disease, who needed a valvulated biological duct. Improvements in the device initially used by Bonhoeffer led to the development of the Melody PV transcatheter.

Currently available transcatheter valve technologies are approved for use in circumferential RVOTs. This is a relatively small percentage of patients $(\sim 20-25 \%)$ with RVOT dysfunction. Off-label use of these valves for nonconduit RVOTs is feasible and increasing; however, there are still patients with an RVOT that is too large to accommodate currently existing valve technology.

Currently there are two valves approved by the FDA for its use in pulmonary position: the Medtronic Melody valve and the Edward's Sapien XT valve.

The Melody valve (Medtronic, Minneapolis, MN, USA) is approved by the US Food and Drug Administration (FDA) for use in patients with a clinical indication for intervention 
Table 1 Surgical treatment after rTOF

\begin{tabular}{|c|c|c|c|c|c|c|c|}
\hline First author (Ref.) & $\begin{array}{l}\text { Sample } \\
(\mathrm{N})\end{array}$ & $\begin{array}{l}\text { 30-day } \\
\text { mortality }\end{array}$ & $\begin{array}{c}5-y r \\
\text { mortality }\end{array}$ & $\begin{array}{l}\text { 5-yr } \\
\text { redo-PVR }\end{array}$ & $\begin{array}{l}\text { Age at TOF repair mean/ } \\
\text { median (SD or range) }\end{array}$ & $\begin{array}{l}\text { Age at PVR mean/ } \\
\text { median (SD or range) }\end{array}$ & $\begin{array}{l}\text { Time interval TOF } \\
\text { repair to PVR mean/ } \\
\text { median (SD or range) }\end{array}$ \\
\hline Jang et al. (28) & 131 & 0 & 0 & 3.5 & NA & $14.8(6.7)$ & $12.5(5.2)$ \\
\hline Frigiola et al. (19) & 73 & 0 & NA & NA & $3.9(5.2)$ & $23.6(11.5)$ & NA \\
\hline Jain et al. (30) & 153 & 4.6 & 3.3 & NA & NA & 33 [18-74] & NA \\
\hline Chen et al. (31) & 227 & 0 & 3 & 6 & $0.8(0.01-37)$ & $19.4(0.4-58.1)$ & $17.5(0.37-46.13)$ \\
\hline Chen et al. (32) & 161 & 1.2 & 1.2 & 6 & NA & NA & NA \\
\hline Cesnjevar et al. (11) & 47 & 2.1 & 2.1 & 6.4 & $5.7(9.2)$ & $19.2(12.2)$ & $13.2(7.4)$ \\
\hline Oosterhof et al. (13) & 71 & 0 & 1.4 & 4.2 & 5 (2.7-7.4) IQR & 29 [23-37] & NA \\
\hline Dos et al. (34) & 116 & 2.5 & NA & 0.86 & 9 [6] & $36[11]$ & NA \\
\hline Zubairi et al. (35) & 169 & 0.6 & NA & 7 & NA & $14.6(0.6-49)$ & $12(0.6-32.1)$ \\
\hline Scherptong et al. (36) & 90 & 0 & 2.2 & NA & $5.8(5.5)$ & $31.4(10.3)$ & NA \\
\hline Gengsakul et al. (37) & 82 & 0 & 2.4 & NA & $9(6.8)$ & $27.9(13.1)$ & $18.9[10]$ \\
\hline
\end{tabular}

TOF, tetralogy of Fallot; PVR, pulmonary valve regurgitation; NA, not available; IQR, interquartile range.

and a dysfunctional RVOT conduit or bioprosthetic valve with $\geq$ moderate $\mathrm{PR}$ and/or a mean RVOT gradient $>35 \mathrm{~mm}$ $\mathrm{Hg}$. Is a transcatheter pulmonary valve (TPV) consisting of a bovine jugular vein sutured inside of a platinum iridium stent. There are currently two available valve sizes: the TPV 20 and the TPV 22. The TPV 20 uses a $16-\mathrm{mm}$ bovine jugular vein and is intended for implantation at no more than $20-\mathrm{mm}$ diameter, whereas the TPV 22 is an $18-\mathrm{mm}$ bovine jugular vein intended for implantation at sizes up to $22-\mathrm{mm}$ diameter. The unexpanded valve height is $30 \mathrm{~mm}$ for the TPV 20 and $28 \mathrm{~mm}$ for the TPV 22. Both valves are deployed using the Medtronic Ensemble delivery system, a $22 \mathrm{~F}$ delivery system using balloonin- balloon technology. FDA approval for implantation in failed bioprosthetic valves was received in 2017.

The SAPIEN XT (Edwards Lifesciences, Irvine, CA, USA) was approved by the FDA in March 2016 for use in dysfunctional RVOT conduits using the same criteria as noted for the Melody valve. The SAPIEN XT consists of a trileaflet bovine pericardial valve inside a cobalt chromium frame and was initially created to use it in the aortic position, as was the Edwards Lifesciences Novaflex delivery system. In comparison to the Melody valve, the SAPIEN XT is shorter.

A careful evaluation before the procedure is necessary for a successful PPVI and requires the help of imaging specialists. Echocardiography is used to evaluate the systolic and diastolic function of both ventricles, as well as their measurements. The CMR image is indicated for the assessment of RV volume, RVOT morphology and suitability for PPVI.

Because of variability in coronary anatomy among this patients, approximately $5 \%$ of PPVI candidates are at risk for coronary compression after valve deployment and RVOT expansión (39). To avoid this complication, is necessary to perform acoronary angiography with simultaneous balloon inflation in the valvular landing zone. PPVI is contraindicated if coronary flow is impaired during this action.

\section{Complications in PPVI}

\section{Stent fracture}

It is the first cause of either percutaneous or surgical reintervention due to hemodynamic compromise from RVOT 
obstruction (40,41). This occurs because of dynamic recoil of the RVOT at the cardiac cycle, overstressing the stent struts, leading to stent fracture (42).

Stent fracture is classified as type I (no loss of stent integrity), type II (loss of stent integrity), and type III (separation or embolization of the fractured segment) (43). Most of stent fractures are type I and can be managed without surgery (44).

Cabalka et al. analyzed data from the prospective North American and European Melody valve trials and reported stent fractures occurring in 81 of 251 (32\%) implanted patients after a median follow up of 5 years. This study demonstrated that prestenting decreased the risk of stent fracture and that this risk was further reduced by the placement of multiple prestents. $53 \%$ of patients received multiple prestents and only $7 \%$ experienced a subsequent stent fracture, with 2 of these requiring reintervention (45).

\section{Conduit rupture}

Is a relatively common adverse event associated with rehabilitation of obstructed conduits and occurs in 19.5\% to $22 \%$ of patients undergoing angioplasty $(46,47)$. RVOT dissection or conduit rupture usually occurs due to wire perforation or balloon inflation, which can result in a morbidity and mortality increase. Fortunately, the majority of these ruptures are not clinically significant and do not lead to hemodynamic instability.

A multicenter study classified conduit rupture by severity as grade 0 (absent), grade 1 (minimal rupture), grade 2 (moderate but contained), grade 3 (severe with hemodynamic instability requiring blood transfusion) (48).

Rupture occurs more often in heavily calcified conduits. Most of the ruptures can be managed with placement of a covered stent, without open surgery (49). However, in severe cases with hemodynamic compromise, surgery may be required (50).

The Pulmonary Artery Repair With Covered Stent trial was a prospective multicenter trial assessing the safety and efficacy of using the Covered CP Stent (CCPS; NuMED, Inc) to treat conduit injury in patients undergoing intended Melody valve implantation. Conduit tears occurred in $19.5 \%$ of patients overall, with potentially life-threatening conduit tears in $1 \%$ of patients overall. Risk factors for conduit tears included smaller mean conduit diameter at implant, smaller angiographic conduit diameter before intervention, larger ratio of balloon diameter at time of injury to mínimum angiographic diameter prior to any intervention, smaller minimum angiographic diameter/ implant diameter, and higher baseline peak RVOT gradient. The CCPS was effective in treating $95 \%$ of conduit tears. Of the six patients with severe conduit tears, four were successfully treated with the CCPS (46).

\section{Coronary compression}

It is a potential complication preventing PPVI in approximately $5 \%$ of patients (39). It should always be assessed during the procedure. This is accomplished by simultaneously performing balloon angioplasty on the conduit (at the intended size of PPVI) while also assessing the coronary arteries with either ascending aortography or selective coronary angiography.

\section{Endocarditis}

PPV-specific endocarditis is defined by a vegetation visualized on the implant or evidence of new PPV dysfunction in the setting of a blood-stream infection. The rate of a first episode of endocarditis is $2.4 \%$ per patient-year, with a rate of $0.88 \%$ per patient-year for TPVI-related endocarditis (51).

Other recent meta-analysis shows a pooled incidence of endocarditis, as low as 0.6 per 100 person-years for PPV-specific endocarditis and 1.4 per 100 person-years overall (52). This patients can be safely managed with antibiotics. Worse cases may require surgical explantation of the valve (51). Continued screening and having in mind the risk for endocarditis are necessary during follow-up of any patient receiving a PPVI.

\section{Clinical outcomes of PPVI}

The 2010 guidelines from the European Society of Cardiology and Association for European Pediatric Cardiology recommend PPVI with the same indications as surgical PV replacement (8).

Boshoff et al. (53) reported 23 off-label cases of PPVI. The peak RVOT gradient was significantly decreased, and no more than mild PR was observed in a mean followup of 1.2 years. A second procedure because of restenosis were required in 2 patients. There were no vascular complications, SF, or valve migration during follow-up.

Cheatham et al. reported outcomes of the US Investigational Device Exemption trial out to 7 years after PPVI in 150 patients who received a Melody valve implant (54). The authors showed that primary valve failure is rare, and TPV dysfunction is primarily manifested by 
Table 2 Percutaneous treatment after rTOF

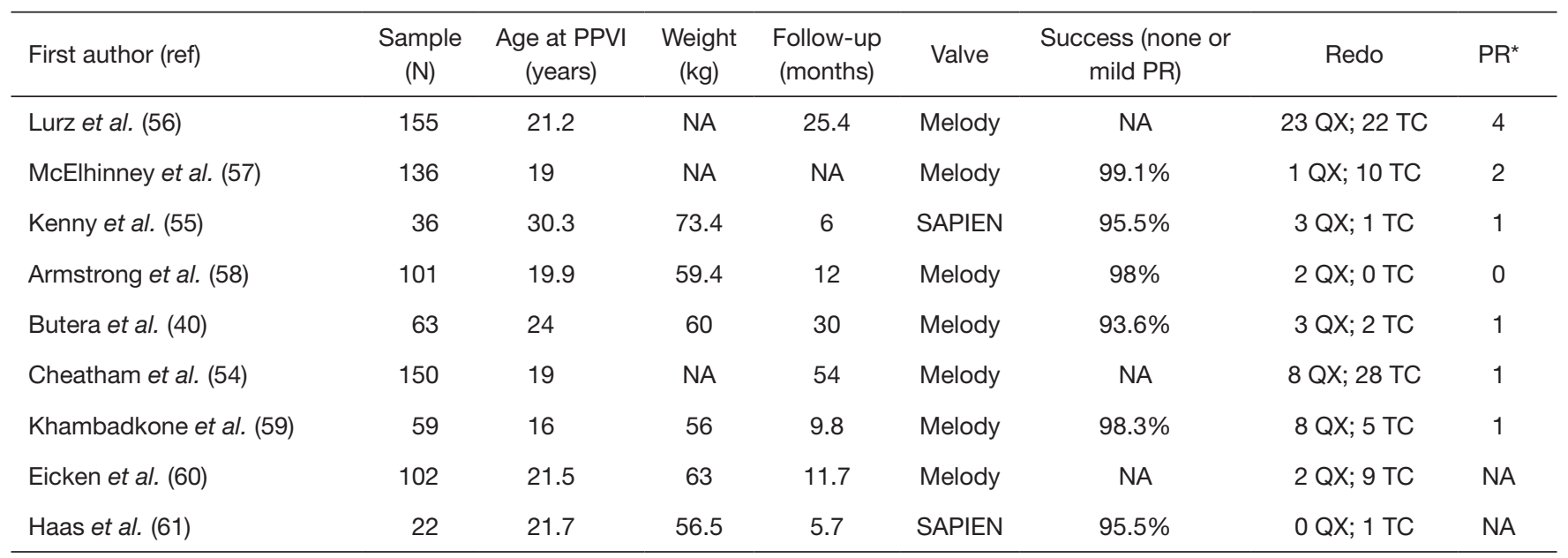

*, moderate or severe pulmonary regurgitation at latest follow-up. PPVI, percutaneous pulmonary valve implantation; PR, pulmonary regurgitation; QX, surgical; TC, transcatheter.

stent fracture, loss of structural integrity, and recurrent stenosis. They also documented freedom from Melody valve reintervention of $76 \%$ at 5 years follow-up. Patients who did not receive a prestent-bare metal stent(s) implanted prior to valve implantation, had a preimplantation gradient $>35 \mathrm{~mm} \mathrm{Hg}$, and patients with a discharge gradient $>20 \mathrm{~mm}$ $\mathrm{Hg}$ had the shortest freedom from reintervention (HR 3.8; $95 \%$ CI, 1.7-8.7). Freedom from Melody valve explantation was $92 \%$ at 5 years.

The COMPASSION trial was a prospective, nonrandomized, multicenter trial that used the SAPIEN THV to treat dysfunctional RVOT conduits; $91 \%$ of patients received a prestent. The overall device success rate was $95.2 \%$, and absence of reoperation was $97.1 \%$ and $93.7 \%$ at 1 and 3 years, respectively. Freedom from major adverse cardiovascular and cerebrovascular events at 3 years was $87.5 \%$. Similar to the Melody valve, the SAPIEN valve's peak stenosis gradient decreased from $37.5 \mathrm{~mm} \mathrm{Hg}$ at baseline to $18.7 \mathrm{~mm} \mathrm{Hg}$ at 1 month, and this was maintained out to $3 \mathrm{yrs}$ with a peak gradient of $17.8 \mathrm{~mm} \mathrm{Hg}$. Likewise, the percent of patients with more than moderate PR fell from $89.9 \%$ at baseline to $8.8 \%$ at 3 years (55).

Lurz et al. (56) demonstrated positive functional remodelling after PPVI. Right ventricle ejection fraction improved early only in the PS group. Late after procedure, there were no further changes in MRI parameters in either group. In the PS group at cardiopulmonary exercise testing, there was a significant improvement in peak oxygen uptake early, with no further significant change late. In the PR group, no significant changes in peak oxygen uptake from early to late could be demonstrated.

Other studies of PPVI are summarized at Table 2.

\section{Comparison between surgery and PPVI}

Both surgery and PPVI have shown excellent outcomes, but even today, there is no study that compares them directly. Surgery continues to be the gold standard for PVR after rTOF, with a large number of studies that support its good outcomes and long follow-ups. Even so, PPVI is proving to be a safe therapy with good outcomes comparable to those of surgery, although studies with longer follow-ups are still necessary.

\section{Conclusions}

Both surgery and PPVI are good alternatives in PVR after rTOF due to its excellent results. PPVI appears on the scene as a safe and effective alternative to open surgery. There is still a need for greater follow-up in the cohorts of patients undergoing PPVI to be able to match the existing surgical studies to assess the durability of the prosthesis and its results. Studies that directly compare percutaneous treatment versus open surgery are also necessary.

It is necessary to see these two types of techniques as complementary tools in the treatment of our patients and not as competing techniques, perhaps thinking that in the not too distant future, the hybrid technique will become the gold standard in the treatment of this pathology. 


\section{Acknowledgments}

Funding: None.

\section{Footnote}

Provenance and Peer Review: This article was commissioned by the Guest Editor (Daniel Hernández-Vaquero) for the series "Structural Heart Disease: The Revolution" published in Annals of Translational Medicine. The article was sent for external peer review organized by the Guest Editor and the editorial office.

Conflicts of Interest: All authors have completed the ICMJE uniform disclosure form (available at http://dx.doi. org/10.21037/atm.2020.03.81). The series "Structural Heart Disease: The Revolution" was commissioned by the editorial office without any funding or sponsorship. DHVP served as the unpaid Guest Editor of the series and serves as an unpaid editorial board member of Annals of Translational Medicine from Aug 2019 to Jul 2021. The authors have no other conflicts of interest to declare.

Ethical Statement: The authors are accountable for all aspects of the work in ensuring that questions related to the accuracy or integrity of any part of the work are appropriately investigated and resolved.

Open Access Statement: This is an Open Access article distributed in accordance with the Creative Commons Attribution-NonCommercial-NoDerivs 4.0 International License (CC BY-NC-ND 4.0), which permits the noncommercial replication and distribution of the article with the strict proviso that no changes or edits are made and the original work is properly cited (including links to both the formal publication through the relevant DOI and the license). See: https://creativecommons.org/licenses/by-nc$\mathrm{nd} / 4.0 \%$.

\section{References}

1. Report of the New England Regional Infant Cardiac Program. Pediatrics 1980;65:375-461.

2. Fallot E. Contribution a lanatomie pathologique de la maladie bleue (cyanotic cardiaque). Marseille méd 1888;25:77,138,207,341,403.

3. Anderson RH, Jacobs ML. The anatomy of tetralogy of Fallot with pulmonary stenosis. Cardiol Young 2008;18
Suppl 3:12-21.

4. Cooley DA. The first Blalock-Taussig shunt. J Thorac Cardiovasc Surg 2010;140:750-1.

5. Lillehei CW, Cohen M, Warden HE, et al. Direct vision intracardiac surgical correction of the tetralogy of Fallot, Pentalogy of Fallot, and pulmonary atresia defects; report of first ten cases. Ann Surg 1955;142:418-42.

6. Kirklin JW, DuShane JW, Patrick RT, et al. Intracardiac surgery with the aid of a mechanical pump-oxygenator system (Gibbon type): report of eight cases. Proc Staff Meet Mayo Clin 1955;30:201-6.

7. Karl TR, Sano S, Pornviliwan S, et al. Tetralogy of Fallot: Favorable outcome of nonneonatal transatrial, transpulmonary repair. Ann Thorac Surg 1992;54:903-7.

8. Baumgartner H, Bonhoeffer P, De Groot NM, et al. ESC guidelines for the management of grown-up congenital heart disease (new versión 2010). Eur Heart J 2010;31:2915-57.

9. Warnes CA, Williams RG, Bashore TM, et al. ACC/ AHA 2008 guidelines for the management of adults with congenital heart disease: a report of the American College of Cardiology/American Heart Association Task Force on Practice Guidelines (Writing Committee to Develop Guidelines on the Management of Adults With Congenital Heart Disease). Developed in Collaboration With the American Society of Echocardiography, Heart Rhythm Society, International Society for Adult Congenital Heart Disease, Society for Cardiovascular Angiography and Interventions, and Society of Thoracic Surgeons. J Am Coll Cardiol 2008;52:e143-263.

10. Silversides CK, Salehian O, Oechslin E, et al. Canadian Cardiovascular Society 2009 consensus conference on the management of adults with congenital heart disease: complex congenital cardiac lesions. Can J Cardiol 2010;26:e98-117.

11. Cesnjevar R, Harig F, Raber A, et al. Late pulmonary valve replacement after correction of Fallot's tetralogy. Thorac Cardiovasc Surg 2004;52:23-8.

12. Buechel ER, Dave HH, Kellenberger CJ, et al. Remodelling of the right ventricle after early pulmonary valve replacement in children with repaired tetralogy of Fallot: assessment by cardiovascular magnetic resonance. Eur Heart J 2005;26:2721-7.

13. Oosterhof T, van Straten A, Vliegen HW, et al. Preoperative thresholds for pulmonary valve replacement in patients with corrected tetralogy of Fallot using cardiovascular magnetic resonance. Circulation 2007;116:545-51. 
14. Geva T, Gauvreau K, Powell AJ, et al. Randomized trial of pulmonary valve replacement with and without right ventricular remodeling surgery. Circulation 2010;122:S201-8.

15. Lee C, Kim YM, Lee CH, et al. Outcomes of pulmonary valve replacement in 170 patients with chronic pulmonary regurgitation after relief of right ventricular outflow tract obstruction: implications for optimal timing of pulmonary valve replacement. J Am Coll Cardiol 2012;60:1005-14.

16. Bokma JP, Winter MM, Oosterhof T, et al. Preoperative thresholds for mid-to-late haemodynamic and clinical outcomes after pulmonary valve replacement in tetralogy of Fallot. Eur Heart J 2016;37:829-35.

17. Therrien J, Siu SC, McLaughlin PR, et al. Pulmonary valve replacement in adults late after repair of tetralogy of Fallot: are we operating too late? J Am Coll Cardiol 2000;36:1670-5.

18. Therrien J, Provost Y, Merchant N, et al. Optimal timing for pulmonary valve replacement in adults after tetralogy of Fallot repair. Am J Cardiol 2005;95:779-82.

19. Frigiola A, Tsang V, Bull C, et al. Biventricular response after pulmonary valve replacement for right ventricular outflow tract dysfunction: is age a predictor of outcome? Circulation 2008;118:S182-90.

20. Gatzoulis MA, Till JA, Somerville J, et al. Mechanoelectrical interaction in tetralogy of Fallot. QRS prolongation relates to right ventricular size and predicts malignant ventricular arrhythmias and sudden death. Circulation 1995;92:231-7.

21. Dehaki MG, Ghavidel AA, Omrani G, Javadikasgari H. Long-Term Outcome of Mechanical Pulmonary Valve Replacement in 121 Patients with Congenital Heart Disease. Thorac Cardiovasc Surg 2015;63:367-72.

22. Pragt H, van Melle JP, Javadikasgari H, et al. Mechanical valves in the pulmonary position: An international retrospective analysis. J Thorac Cardiovasc Surg 2017;154:1371-8.e1.

23. Caldarone CA, McCrindle BW, Van Arsdell GS, et al. Independent factors associated with longevity of prosthetic pulmonary valves and valved conduits. J Thorac Cardiovasc Surg 2000;120:1022-30; discussion 1031.

24. Oliver JM, Garcia-Hamilton D, Gonzalez AE, et al. Risk factors for prosthetic pulmonary valve failure in patients with congenital heart disease. Am J Cardiol 2015;116:1252-6.

25. Ferraz Cavalcanti PE, Sa MP, Santos CA, et al. Pulmonary valve replacement after operative repair of tetralogy of Fallot: meta-analysis and meta-regression of 3,118 patients from 48 studies. J Am Coll Cardiol 2013;62:2227-43.

26. Nomoto R, Sleeper LA, Borisuk MJ, et al. Outcome and performance of bioprosthetic pulmonary valve replacement in patients with congenital heart disease. J Thorac Cardiovasc Surg 2016;152:1333-42.e3.

27. Lim C, Lee JY, Kim WH, et al. Early replacement of pulmonary valve after repair of tetralogy: is it really beneficial? Eur J Cardiothorac Surg 2004;25:728-34.

28. Jang W, Kim YJ, Choi K, et al. Mid-term results of bioprosthetic pulmonary valve replacement in pulmonary regurgitation after tetralogy of Fallot repair. Eur J Cardiothorac Surg 2012;42:e1-8.

29. Batlivala SP, Emani S, Mayer JE, McElhinney DB. Pulmonary valve replacement function in adolescents: a comparison of bioprosthetic valves and homograft conduits. Ann Thorac Surg 2012;93:2007-16.

30. Jain A, Oster M, Kilgo P, et al. Risk factors associated with morbidity and mortality after pulmonary valve replacement in adult patients with previously corrected tetralogy of Fallot. Pediatr Cardiol 2012;33:601-6.

31. Chen PC, Sager MS, Zurakowski D, et al. Younger age and valve oversizing are predictors of structural valve deterioration after pulmonary valve replacement in patients with tetralogy of Fallot. J Thorac Cardiovasc Surg 2012;143:352-60.

32. Chen XJ, Smith PB, Jaggers J, et al. Bioprosthetic pulmonary valve replacement: contemporary analysis of a large, single-center series of 170 cases. J Thorac Cardiovasc Surg 2013;146:1461-6.

33. Therrien J, Siu SC, Harris L, et al. Impact of pulmonary valve replacement on arrhythmia propensity late after repair of tetralogy of Fallot. Circulation 2001;103:2489-94.

34. Dos L, Dadashev A, Tanous D, et al. Pulmonary valve replacement in repaired tetralogy of Fallot: determinants of early postoperative adverse outcomes. J Thorac Cardiovasc Surg 2009;138:553-9.

35. Zubairi R, Malik S, Jaquiss RDB, Imamura M, Gossett J, Morrow WR. Risk factors for prosthesis failure in pulmonary valve replacement. Ann Thorac Surg 2011;91:561-5.

36. Scherptong RWC, Hazekamp MG, Mulder BJM, et al. Follow-up after pulmonary valve replacement in adults with tetralogy of Fallot: association between QRS duration and outcome. J Am Coll Cardiol 2010;56:1486-92.

37. Gengsakul A, Harris L, Bradley TJ, et al. The impact of pulmonary valve replacement after tetralogy of Fallot repair: a matched comparison. Eur J Cardiothorac Surg 
2007;32:462-8.

38. Bonhoeffer P, Boudjemline Y, Saliba Z, et al. Percutaneous replacement of pulmonary valve in a right-ventricle to pulmonary-artery prosthetic conduit with valve dysfunction. Lancet 2000;356:1403-5.

39. Morray BH, McElhinney DB, Cheatham JP, et al. Risk of coronary artery compression among patients referred for transcatheter pulmonary valve implantation: a multicenter experience. Circ Cardiovasc Interv 2013;6:535-42.

40. Butera G, Milanesi O, Spadoni I, et al. Melody transcatheter pulmonary valve implantation. Results from the registry of the Italian society of pediatric cardiology. Catheter Cardiovasc Interv 2013;81:310-6.

41. Ansari MM, Cardoso R, Garcia D, et al. Percutaneous pulmonary valve implantation. J Am Coll Cardiol 2015;66:2246-55.

42. Cosentino D, Capelli C, Pennati G, et al. Stent fracture prediction in percutaneous pulmonary valve implantation: a patient-specific finite element analysis. Berlin, Heidelberg: Springer, 2011:288-93.

43. Nordmeyer J, Khambadkone S, Coats L, et al. Risk stratification, systematic classification, and anticipatory management strategies for stent fracture after percutaneous pulmonary valve implantation. Circulation 2007;115:1392-7.

44. Demkow M, Biernacka EK, Śpiewak M, et al. Percutaneous pulmonary valve implantation preceded by routine prestenting with a bare metal stent. Catheter Cardiovasc Interv 2011;77:381-9.

45. Cabalka AK, Hellenbrand WE, Eicken A, et al. Relationships Among Conduit Type, Pre-Stenting, and Outcomes in Patients Undergoing Transcatheter Pulmonary Valve Replacement in the Prospective North American and European Melody Valve Trials. JACC Cardiovasc Interv 2017;10:1746-59.

46. Delaney JW, Goldstein BH, Bishnoi R, et al. PARCS Investigators. Covered CP Stent for Treatment of Right Ventricular Conduit Injury During Melody Transcatheter Pulmonary Valve Replacement. Circ Cardiovasc Interv 2018;11:e006598.

47. Hainstock MR, Marshall AC, Lock JE, et al. Angioplasty of obstructed homograft conduits in the right ventricular outflow tract with ultra-noncompliant balloons: assessment of therapeutic efficacy and conduit tears. Circ Cardiovasc Interv 2013;6:671-9.

48. Boudjemline Y, Malekzadeh-Milani S, Patel M, et al. Predictors and outcomes of right ventricular outflow tract conduit rupture during percutaneous pulmonary valve implantation: a multicentre study. EuroIntervention 2016;11:1053-62.

49. Berman DP, McElhinney DB, Vincent JA, et al. Feasibility and shortterm outcomes of percutaneous transcatheter pulmonary valve replacement in small. Circ Cardiovasc Interv 2014;7:142-8.

50. Ghawi H, Kenny D, Hijazi ZM. Transcatheter pulmonary valve replacement. Cardiol Ther 2012;1:5.

51. McElhinney DB, Benson LN, Eicken A, et al. Infective endocarditis after transcatheter pulmonary valve replacement using the Melody expert review of cardiovascular therapy 205 valve: combined results of 3 prospective North American and European studies. Circ Cardiovasc Interv 2013;6:292-300.

52. Chatterjee A, Bajaj NS, McMahon WS, et al. Transcatheter pulmonary valve implantation: a comprehensive systematic review and metaanalyses of observational studies. J Am Heart Assoc 2017;6:e006432.

53. Boshoff DE, Cools BL, Heying R, et al. Off-label use of percutaneous pulmonary valved stents in the right ventricular outflow tract: time to rewrite the label? Catheter Cardiovasc Interv 2013;81:987-95.

54. Cheatham JP, Hellenbrand WE, Zahn EM, et al. Clinical and hemodynamic outcomes up to 7 years after transcatheter pulmonary valve replacement in the US melody valve investigational device exemption trial. Circulation 2015;131:1960-70.

55. Kenny D, Rhodes JF, Fleming GA, et al. 3-Year Outcomes of the Edwards SAPIEN Transcatheter Heart Valve for Conduit Failure in the Pulmonary Position From the COMPASSION Multicenter Clinical Trial. JACC Cardiovasc Interv 2018;11:1920-9.

56. Lurz P, Coats L, Khambadkone S, et al. Percutaneous pulmonary valve mplantation: impact of evolving technology and learning curve on clinical outcome. Circulation 2008;117:1964-72.

57. McElhinney DB, Hellenbrand WE, Zahn EM, et al. Short- and medium-term outcomes after transcatheter pulmonary valve placement in the expanded multicenter US Melody valve trial. Circulation 2010;122:507-16.

58. Armstrong AK, Balzer DT, Cabalka AK, et al. One-year follow-up of the Melody transcatheter pulmonary valve multicenter post-approval study. JACC Cardiovasc Interv 2014;7:1254-62.

59. Khambadkone S, Coats L, Taylor A, et al. Percutaneous pulmonary valve implantation in humans: results in 59 consecutive patients. Circulation 2005;112:1189-97.

60. Eicken A, Ewert P, Hager A, et al. Percutaneous 
pulmonary valve implantation: two-centre experience with more than 100 patients. Eur Heart J 2011;32:1260-5.

61. Haas NA, Moysich A, Neudorf U, et al. Percutaneous implantation of the Edwards SAPIEN pulmonic valve: initial results in the first 22 patients. Clin Res Cardiol 2013;102:119-28.

Cite this article as: Meca Aguirrezabalaga JA, Silva Guisasola J, Díaz Méndez R, Escalera Veizaga AE, Hernández-Vaquero Panizo D. Pulmonary regurgitation after repaired tetralogy of Fallot: surgical versus percutaneous treatment. Ann Transl Med 2020;8(15):967. doi: 10.21037/atm.2020.03.81 